\title{
THE INTERACTIVE ART SYSTEM
}

\author{
Stroud Cornock \\ Higher Education Consultancy \\ 4 Russell Road \\ London \\ $\mathrm{N} 8 \mathrm{HHN}$ \\ $\mathrm{UK}$
}

A formative journey from encounters with signals intelligence and cybernetics to work with colleagues, students and engineers between March 1968 and June 1972 on interactive art systems that seemed (40 years ago) to be significant. Though widely exhibited, in once case at the VI Paris Biennale, the programme was aborted in 1972 for the lack of arts research and development funding. Two conceptual frameworks: the artwork as a system; and what an engineer termed the art work's 'logic engine'. The paper asks whether the time of these ideas did, should or ever will come.

\section{AN EPIPHANY}

In late 1967 or early 1968 the Sunday Times invited sculptors to compete for the opportunity to have one or two sculptures commissioned for a concourse through Woolgate House, a new development in the City of London. This was to be my first experience of documenting an architectural site where, as I drew, took measurements and photographs, I suddenly saw my father striding through the precinct. In the same instant I knew it was not he (my parents had recently moved to the West country). Nevertheless, in that instant, I had suddenly seen my sculptural oeuvre in what had been his stamping ground for 40 years, and through his eyes. The eyes, we might say, of Everyman.

Some years later, as a research student at Lancaster, I modelled the art world as a population of 'tribes' (painters, critics, historians, curators, and so on). One of these was the contemporary (then thought of as Modern) art world, constituted as a tiny international coterie of Artforum readers - artists, curators, critics - who conducted a kind of debate through the primary medium of the exhibition. On that day at Woolgate House I had exiled myself from the contemporary art tribe! Having experienced an epiphany, what presented itself was a new problem: how to engage and, more important to sustain the attention of Everyman? How to involve those who knew little of the issues so earnestly debated in the private views and art press? (It is worth noting here that, four years later, the remoteness of art world debate from the general public was dramatised when news of the acquisition of 120 standard bricks by the Tate Gallery reached the tabloid press.)

The answer to the new problem would not, I conjectured, be authored entirely by myself as the sculptor, and any sense of meaning would have to come from somewhere other than the debate so earnestly carried on in the pages of Artforum; instead, it would have to arise out of whatever was going on at Woolgate House, including the comings and goings of folk just like my father. 
At the age of 16 I had gone to art school. In the 1950s one learned to draw. How to represent forms such as the human body, landscapes and architectural structures, very much in the spirit and using the techniques of the Italian renaissance. Then I went off into signals intelligence with the Far East Air Force, which fed a natural preoccupation with what Harold Wilson was to call the 'white heat of technology'. I returned to Britain to study sculpture further, and went on to practice and exhibit. But it took me until 1967 to finally grasp a sense of artistic identify. In that year I established a vocabulary of forms, and a kind of logic or narrative linking a body of works. Then, just as I was beginning to exhibit these new sculptures, the epiphany swept it all away!

\section{BANDERSNATCH}

In September 1965 I had joined a team led by Roy Ascott at a college of what is now a university in East Anglia [1]. There I was immediately confronted with something called cybernetics. This (and an accompanying battery of terms) was both mystifying and beguiling as the Jabberwocky and the frumious Bandersnatch, invented by Charles Dodgson to amuse his young companion Alice Liddell. Ascott referred me to a paper on the topic [2]. From there I progressed to the works of Norbert Weiner and later worked with members of the Open University Systems Group before embarking on research in the field at the Lancaster University's Department of Systems. I mention this strand of the story because the concept of systems is so fundamental to the responsive class of artwork discussed here.

Heraclitus prefigured systems thinking when he spoke of a river as a process rather than a thing. This conceptual framework has continued to draw on a variety of disciplines in enabling us to think about, to model and manage such processes; they involve organic and inorganic control, human organisations and the geophysical environment [3], [4], [5], [6]. In the realm of the visual arts the process-oriented approach was informed by an exhibition held at the Tate Gallery London in 2005 [7]. But another and distinct set of cultural and artistic connotations of the term 'system' exists, with strong links to mathematics and logic. In the realm of music one thinks of canonical fugue, serialism and the early works of Steve Reich; while in the visual arts the associations would be with tessellations, logic, chance and order [8]. These two distinct uses within the art world reflect a general bifurcation of the uses of the term 'system'; mention has already been made of a process-oriented strand of systems thinking but, when the term 'system' began to find wide usage, it was in the context of engineering and organisational design, after WWII.

Broadly, then, there are quantitative and qualitative and approaches (that is, of course, an over simplification) one rooted in mathematics and engineering, and the other arising out of efforts to describe natural processes - each associated with a distinct pattern of artistic activity.

\section{GEMINI}

The Woolgate House concourse was long enough to separate two sculptural sites by more than 100 feet. It was open to the sky, and used both by employees and by members of the public passing through. What this suggested was a pair of structures that regulars might begin to perceive as able to reflect not only the seasons (as might a 


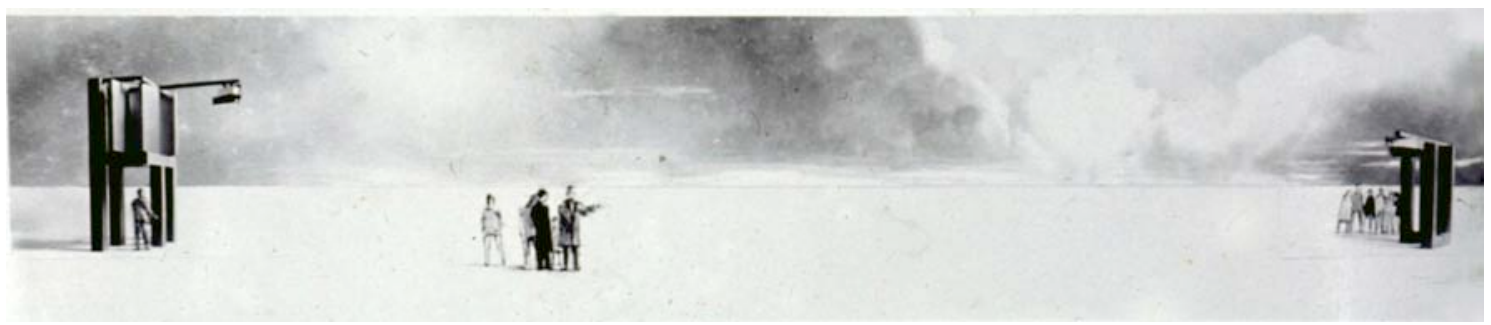

Figure 1. Photomontage made using scale maquettes of Gemini structures.

deciduous tree) and diurnal rhythms (as is the case with many flowers) but also to make some contribution to the life of the concourse, as the flow of visitors waxed and waned.

Drawing on a system theoretic model of the situation, my first instinct was to look for some very straightforward forms of input and output. On the input side the technology was familiar (temperature and light sensing, infra-red beam detection paths). The use of electrical power had been greatly refined since WWII to enable the engineer to achieve smooth and controlled movement; halogenic with dimmer controls and powerful, directional beams had become available.

As a description of the raw materials for an art work this sounds cold, mechanical and uninviting. The antithesis of the artist's supposed inner turmoil. But subtlety would lie not in the fact of light or movement, but in the ability of the viewer to detect pattern. To treat the sum of the mechanical outputs over time as behaviour and, crucially, behaviour perhaps subtely related in some yet-to-be-determined way, to something in the environment.

This points ahead to readings around human psychology, for such an artwork would be predicated on our human predisposition to look for more or less meaningful patterns in stimuli encountered. It was central to this whole line of work that there be such a predisposition, that it be strong and that it be universal. [9]

\section{THE LOGIC ENGINE}

Having formulated a strategy for a pair of mechanical devices equipped with sensors and activators I somehow came across a young Canadian engineer who fizzed with enthusiasm and ideas for the project. As I rambled about the need to mediate between inputs and outputs so as to detect and to impose pattern, his response was laconic: "Stroud, what we need is a logic engine!" At the time the word 'computer' was limited in its associations with large American businesses (or it was in my mind - we need to remember that this well before we learned of the work of Alan Turing at Bletchley Park). Three years before the Woolgate House epiphany I had received IBMs Eastern Region Data Processing Manager at what is now a college of an East Anglian university to discuss the Media Handling concept. But computers were something seen in American films, as reel-to-reel magnetic tape drives rocked to and fro. Later I was taken into the bowels of an IBM office on Newman Street to see what was proudly proclaimed to be the first example of the successor technology in Europe: a disc drive the size of a washing machine into which was inserted a stack of plastic dinner plates. Even then I have no recollection of seeing the computer itself - one had little idea of how many boxes, cables, lamps and so on constituted such a device. It was around 
1970 that I watched something called a Stantec Zebra being wheeled away on sack trucks to the waste disposal and entered a corridor whose internal windows looked onto a succession of cabinets in an air-conditioned suite devoted to the Stantec's successor a Boroughs mainframe. Shortly afterwards, my colleagues and I gained direct access to a Honeywell DDP-516.

One respect in which this proposal was an 'idea before its time' is that it needed to be put forward as a development project. Traditionally a proposal would commence with a visualisation in the form of a drawing or maquette; an aesthetic judgement would then be made and only then would practical questions that might involve engineering be addressed. In this case however, any judgment on the merit of what was proposed would require attention to a narrative account of the processes that the proposed structures were there to support, plus some sort of initial evaluation of the engineering
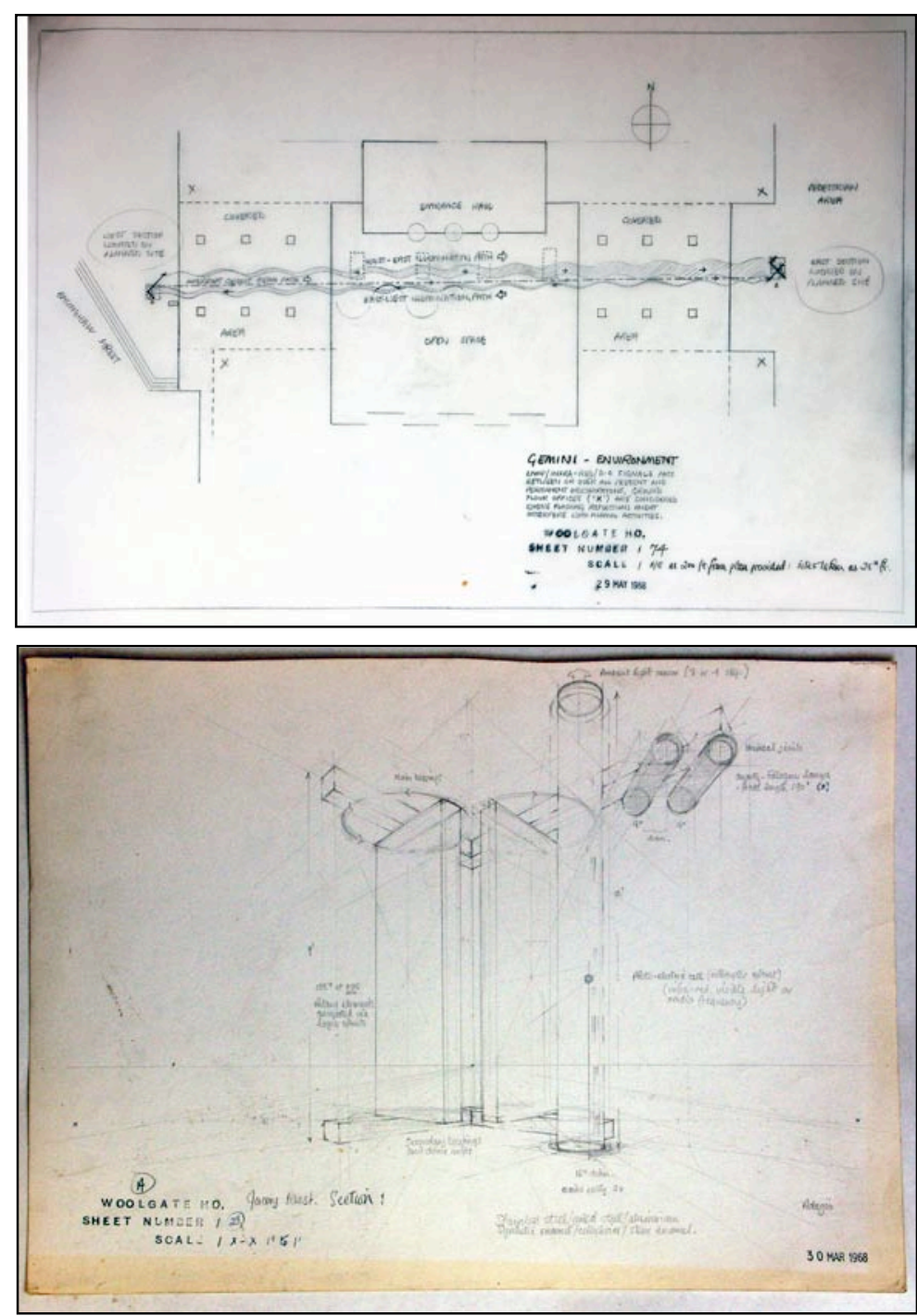

Figures 2 and 3. Sheets 23 and 74 from the set of materials submitted as the Gemini project.

distinct output patterns. drawings,

circuit

diagrams,

safety

provisions proposed, and so on. It would have been literally impossible for the judges to look at maquettes and see what was proposed, or even to realise that they were related. But that is what happened: each maquette (in steel, aluminium, paint and additional elements) was placed on a short list, but the plans and descriptions were left unopened.

Both had been selected on a set of criteria that had been consciously excluded in their conception!

The author undertook no programming in drawing up proposals for projects. Instead, a careful narrative description was drawn up in each case, so that Nealson's logic engine could be developed to identify input patterns and generate a repertoire of 
This was an approach that was successfully used in encouraging art and design students to explore the possibilities of early computer graphics at Leicester around 1970. The area had a certain glamour, but was dangerous in that it was only a minority who could devote the tremendous effort and time required to achieve useful results by programming using the systems then available. Others were spending an inordinate amount of time attempting to write vector graphic routines. Even to specify and then output simple shapes - squares, triangles and spirals - would require pages of coding, the production of punched cards and paper tape and waiting for hours for a printer to churn out inked line segments on sprocketed paper rolls. As with other technical vogues (such as the vacuum forming machine), the result might have little to do with learning about fine art practice. The author was an expert in drawing and had helped to set up the university's first computer centre. (What was at the time City of Leicester Polytechnic, now De Montfort University, convened a committee whose report led, around 1969, to the establishment of a Computer Centre with a staff of engineers and programmers).

Together with a recently appointed Chief Programmer, a project was mounted to create software (dubbed \$ART) allowing the user to record a number of entries via a newlyacquired graphic digitizing tablet, manipulate them (scale, rotate, group, etc.) and store the results for outputs via VDU and plotter.

This all sounds obvious now, but the author was aware of only three related systems. One was a programme called PICASO that was being developed at Middlesex [10]; the second was an architectural visualisation system realised in the USA [11]; finally, there was a wonderful but costly digitizer-plotter, developed and marketed by Imperial College [12]. Of these the only accessible system was PICASO; perhaps unfortunately, it had been described to the author as a menu-driven library of ready-made shapes (coke bottle, Africa, and so on) to be manipulated by people who could not draw.

The other thing to say about the author's emphasis on the 'logic engine' as a tool with

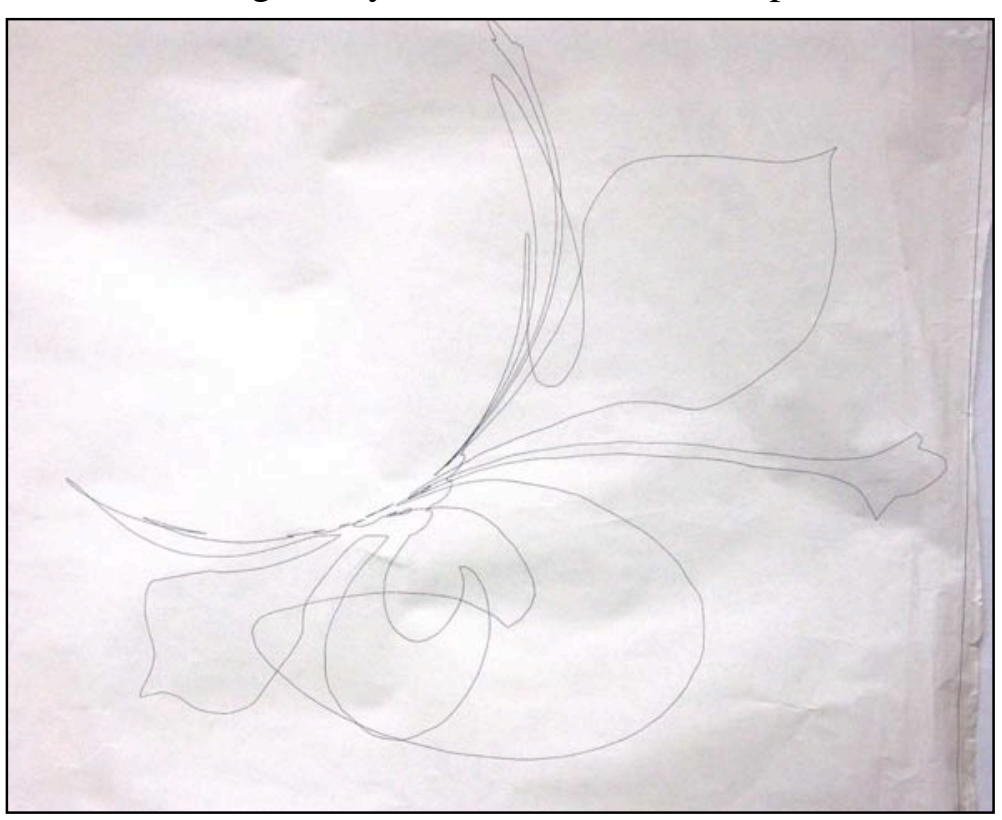

Figure 4. Digitized image of Florentine lily made using the \$ART software. A number of distortions were requested by the painter Tom Phillips, in preparing illustrations for his translation of Dante's which to manage the pattern of inputs and outputs is that the only realised example seen by the author during this period (i.e. designed, built at full scale, programmed and then operated in a public space) was Edward Ihnatowicz's Senster. The author spoke with Edward in the engineering department of University College London, where the Senster was under construction, and also visited the work when it was installed at Philips Evoluon in Eindhoven. 
Sadly, it appeared to have been a deeply frustrating project for the sculptor: the system appeared to have been treated by Philips as a mechanical toy. Schoolchildren were regularly crowded around the piece, waving and shouting as it went through a repertoire restricted both by Philips and by the system's inability to cope with the overload. Edward himself, anxious of course to explore various patterns of inputs so as to tune the system's responses, was frustrated by the limitations imposed on him by Philips' staff, and was later excluded altogether. [13]

\section{FIVE PROJECTS}

Some time around 1970 my colleague Ernest Edmonds recommended use of the term 'interactive' to describe the management, via a human-computer interface, of the pattern of inputs and outputs by the decision-making device used in an artwork (Nealson's logic engine), and some of the implications were subsequently unpacked by the author [14]. Between 1968 and 1972 a number of interactive art systems and projects were exhibited, of which those summarily described below (in chronological sequence) are those involving computer management. Datapack is important because it ran as a live demonstrator - out of Leicester Polytechnic on a Honeywell DDP-516, and at Computer Graphics 70 on a GEIS terminal, in both cases to plotter outputs. The projects were otherwise represented in scale models, drawings, descriptions and technical plans exhibited at the VI Paris Biennale (Musée de l'Art Moderne, Paris, 1969), Event One (Royal College of Art, 1969), The Invention of Problems (Leicester Polytechnic, 1970), The Invention of Problems II (Leicester Polytechnic, 1971), Cognition and Control (Midland Group Gallery, 1972) and Kinetics (Glynn Vivian and Talbot Rice galleries, 1972).

\section{Gemini (1968)}

The first of the projects, described earlier, was undertaken in collaboration with Nick Nealson, a Canadian electronics engineer.

\section{Datapack (1969)}

The second project, designed and realized in collaboration with Ernest Edmonds in 1969, was described and exhibited at the Computer Graphics 70 conference [15].

\section{Interplay (1969)}

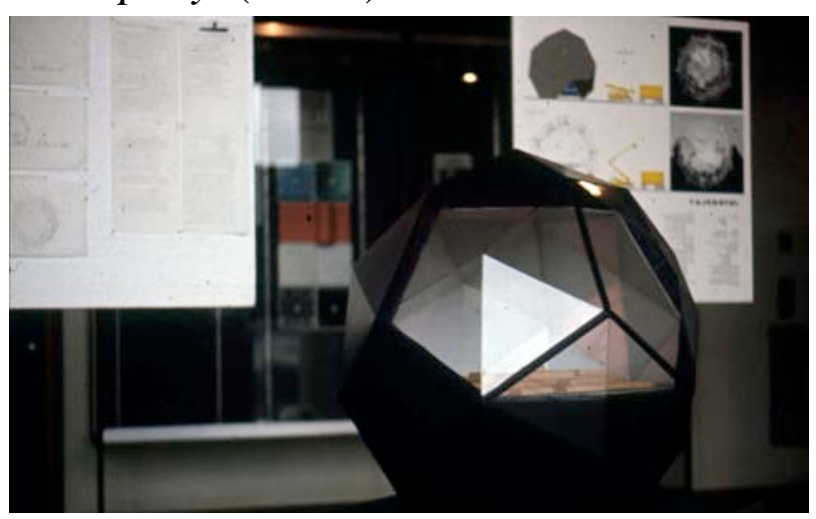

A group including an architect, artists, designers and an engineer devised this ambitious scheme. The group divided into two teams to design and build a structural model and a simulator that were exhibited, together with engineering studies, as a project for an environmental and computermanaged scheme for adult creative participation.

Figure 5. Interplay simulator and supporting documentation. 


\section{Machina Ludens (1971)}

A group divided into two teams to design and build a simulation of a computermanaged scheme for adult creative participation, and produce a video document for exhibition.

\section{Rover (1971-72)}

This research and development project was conceived jointly with Ernest Edmonds as electromechanical test bed for studying the psychology of art and interaction. In order to achieve high resolution in driving an interactive visual display in three dimensions an

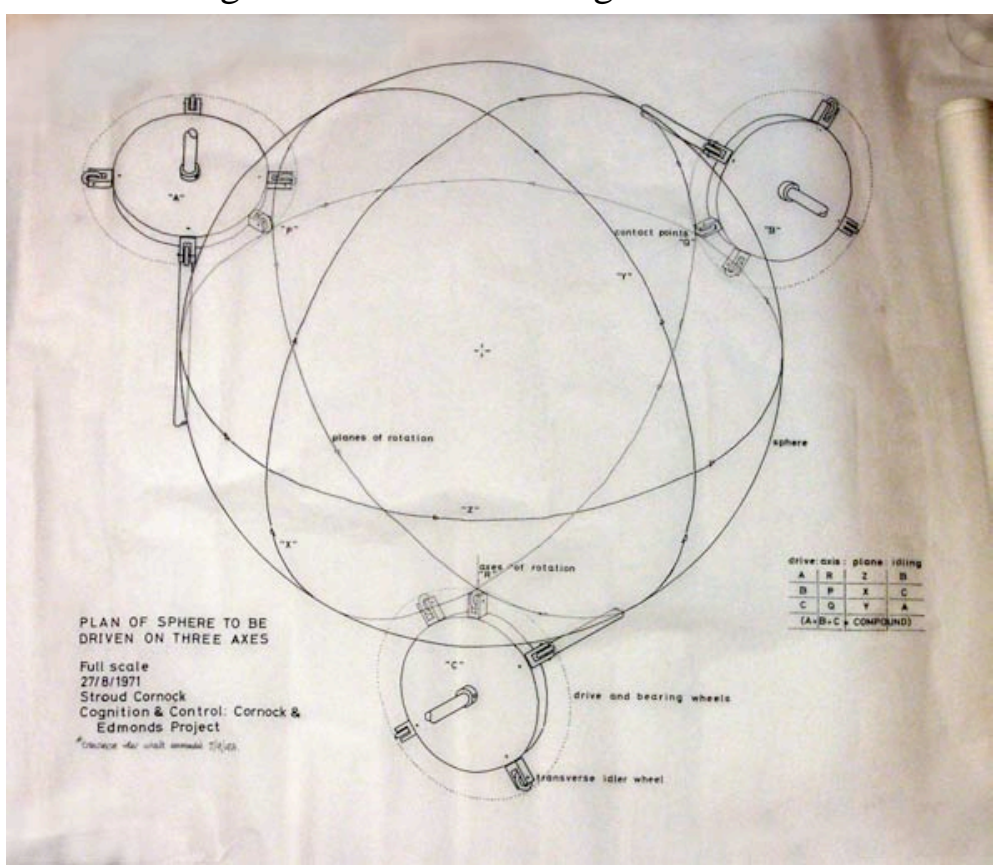

Figure 6. Working drawing for the Rover project

showing the sphere supported by orthogonal drive wheels. analogue test bed was configured as a pyramid supporting three axles driving large diameter wheels on the rims of which were mounted transverse idler wheels. Viewed at close range under controlled lighting conditions the surface could be moved with three degrees of freedom on the $\mathrm{X}, \mathrm{Y}$ and $\mathrm{Z}$ axes. The decision to take the nalogue route was an acknowledgement of the fact that the project was before the time of personal or even local computing.

\section{EVALUATION}

What value might be assigned to the ideas underlying the projects described? Earlier it was suggested that the contemporary art world has the character of a debate - a restricted debate, where the aim of all of the participants is to influence or to set the agenda. In this sense the achievements of Marcel Duchamp - scanty when measured in terms of wider public fame, representation on the walls of public art galleries and in the value of auction sales - can be said to rival those of Picasso. But none of the projects described in this paper had the slightest impact on the course of the debate that is art. More ominously (though the author has continued to visit public and private exhibitions of art, including surveys such as the Frieze Art fair), works involving managed interaction have rarely been encountered and have certainly not achieved a high profile. Numerous examples of both projected and realised interactive works are to be found online, with a history stretching back over a quarter of a century. But such work does not appear to have the status of a movement, or genre; more that of a curiosity. As Riccardo Rabagliati stated when introducing a body of work in the Venice Biennale art 
exhibition: "Interactive works of art having a digital basis are still confined to specialized events; very few of them are yet represented in the main contemporary art museum and international shows of art." [16] Such ideas have not received the blessing of Charles Saatchi, the Lorenzo de' Medici of our time (Saatchi does, however, claim the world's largest interactive art gallery).

There are some related developments that have achieved some prominence, one of them being the introduction of physical movement into the form of the art object. An early example is provided by the work Kinetic Composition, produced in 1920 by Naum Gabo. In the mid-1930s Alexander Calder used small electric motors to drive structures he called his mechanical ballet. But Calder seems to have rejected this in favour of breeze-driven mobiles. This I take to be a rejection of the central proposition of Kinetic Art: that motion in some way contributes to the artistic merit of a work. Facts concerning a medium - pencil, brush or chisel - do not, of course, confer such merit; but they can help to give a work its distinct form, as in the case of etching, and clay modelling. What the projects described argued is that the advent of information processing introduced the possibility of an artwork that can function as an open system: a system that initiates interactions with its environment. This all seemed portentous at the time [17], [18], [19], but the moment for such a fully-realised interactive art system is yet, if ever, to come.

(Photographs by the artist.)

\section{References}

[1] MASON, C: A Computer in the Art Room, JJG Publishing, Norfolk, 2008. Chapter 4, pp. $66-78$.

[2] ASCOTT, R: Behaviourist Art and the Cybernetic Vision. 1964, Cybernetica: Journal of the International Association for Cybernetics, Namur.

[3] BERNARD, C: An Introduction to the Study of Experimental Medicine, 1865. First English translation by Henry Copley Greene, published by Macmillan \& Co., Ltd., 1927; reprinted in 1949.

[4] WEINER, N: Cybernetics, Cambridge, MS: M.I.T. Press, 1948.

[5] CHECKLAND, P: Systems Thinking, Systems Practice, London: Wiley, 1981.

[6] MEADOWS, D.L, Meadows, D, Randers, J and Behrens III, W: The Limits to Growth. New York: Universe Books, 1972.

[7] TATE GALLERY: exhibition Open Systems, 2005. See web page $<$ http://www.tate.org.uk/modern/exhibitions/opensystems/>

[8] MARTIN, K: Chance and Order, a series 1960s - 1980s. <http://fineart.ac.uk/artists.php?idartlist=50 November 2009>.

[9] BOWER, T.G.R: Learning in Infancy, 1974, Freeman, London.

[10] MASON, C: Op Cit. Chapter 7, pp. 147 -153.

[11] SUTHERLAND, I: Sword of Damocles - the first virtual reality system. Summary description given on Wikipedia webpage <http://en.wikipedia.org/wiki/The_Sword_of_Damocles_\%28virtual_reality\%29 $>$

[12] CADMAC: a digitizer-plotter supporting image manipulation developed at Imperial College. Described in Design Journal in 1971, available online at 
$<$ http://vads.ahds.ac.uk/diad/article.php?year=1971\&title=266\&article=d.266.38

[13] MASON, C: Op Cit. Chapter 5, pp. 79 - 99.

[14] CORNOCK, S: Interacting with a Work of Art. 1975, Progress in Cybernetics and Systems Research, 2, Trappl and Hanika (Editors). Hemisphere, 1975, 186191.

[15] CORNOCK, S and E. Edmonds: The Creative Process Where the Artist is Amplified or Superseded by the Computer, paper presented at Computer Graphics 70 and further published in Leonardo, 4, 1973, 11-16. Reprinted in Malina (Editor). Visual Art, Mathematics and Computers, Pergamon, pp. 287 291.

[16] RABAGLIATI, R: paper delivered Dean of the Accademia di Belle Arti at the Venice Biennale, 2006. See web announcement <http://www.dsi.unive.it/avi2006/program.htm>

[17] CORNOCK, S: The Role of the Artist in a Post-lndustrial Society: A Systems Approach, Cybernetics and Systems Research, Hanika and Roszenitch (Editors). 2, Transcripta, 1973, 413-420

[18] CORNOCK, S: Towards a General Systems Model of the Artistic Process, Control Magazine, 6, 1972, \#-6

[19] CORNOCK, S: The Cultural Impact of Interactive Computing, Online 72, 1, 1972, 93-112 